\title{
Formation of the personal meanings of the study of mathematics among students of agricultural areas of training by means of contextual learning
}

\author{
Natalia Biryukova ${ }^{1, *}$ \\ ${ }^{1}$ Feferal State Budgetary Educational Institution of Higher Northern Trans-Ural State Agricaltural \\ University, 625003 Respubliki street, 7, Tyumen, Russia
}

\begin{abstract}
The article presents the results of a study of the influence of contextual teaching methods on the development of personal meanings of teaching university students. Since it is education that provides real opportunities for the development of citizens, their self-realization and demand in modern society, which is being formed today under the influence of the processes of informatization and intellectualization of all spheres of public life, the problem of the formation of value orientations, the meanings of learning is especially relevant. The aim of the research is to find ways and means of forming the personal meanings of students in the study of non-core subjects for their direction, in particular mathematics. The process of teaching mathematics is modeled, providing a semantic orientation of teaching. Three stages of meaning formation with the characteristics of their content are considered. The effectiveness of using a contextual approach to the process of teaching mathematics to students of agricultural areas of training is shown.
\end{abstract}

\section{Introduction}

High-tech electronic technologies of modern production [1] require specialists with a high level of potential for the development and self-development of intellectual abilities, spiritual, moral and professional qualities. The disciplines of the natural science cycle have significant potential for the formation of such a specialist model. Their study contributes to the development of general human culture at the level of its meaningful, conscious understanding and becoming meanings of modern man [2].

From the point of view of the value approach, meaning formation is the most important aspect of developmental education [3]. However, as practice shows, the problem of finding personal meanings exists and is especially relevant in the conditions of the educational process of a university, in the study of non-core disciplines.

\footnotetext{
${ }^{*}$ Corresponding author: n.biriukova@bk.ru
} 
The purpose of the study was to identify ways and means of forming personal meanings in students when studying general education subjects that are not key for their direction of training.

The hypothesis of the research was based on the assumption that the formation of personal meanings of teaching mathematics in students involves the fulfillment of the following pedagogical conditions:

1) the process of teaching mathematics is built taking into account the psychological mechanisms of meaning formation (identification, exteriorization, exteriorization) and on the basis of phased meaning formation: the stage of activation of reflection, a critical attitude to the existing meanings; stage of personal meaning actualization; the stage of stimulating self-realization in the learning process [4];

2) various forms and methods of contextual learning are used in the educational process, such as document analysis, task method, project method, problem learning method.

The theoretical and methodological base of the study was made up of:

1) theoretical analysis of semantic reality (DA Leontiev, AG Asmolov) $[5,6]$;

2) ideas of personality-oriented education (VV Serikov, S.B. Belova) [7, 8];

3 ) the ideas of the contextual approach in teaching (AA Verbitsky and others) [9].

Results of theoretical analysis of the problem:

1) The personal meaning of studying mathematics is a subjective reflection in the minds of students of the objective significance of mathematical education [10].

2) Various forms and methods of contextual learning serve as a means of forming a personal meaning in the study of mathematics.

The research was carried out on the basis of the Federal State Budgetary Educational Institution of Higher Education of the Tyumen State Agrarian University of the Northern Trans-Urals. The experimental group consisted of first-year students of the agrotechnological institute in various fields of training.

\section{Materials and Methods}

Diagnostics of the formation of personal meanings of education was carried out on the basis of comparing the following research methods: theoretical (problem analysis, modeling); empirical (observation, survey, analysis of the products of activity).

The simulated learning process was tested in a formative experiment. In the experiment, with the help of various forms and methods of contextual learning, the techniques of creating situations were tested, aimed at the formation of individual, personal meanings of studying the subject.

The purpose of the first stage of the experiment was to form a semantic position in the subjects towards the process of studying mathematics. The means of achievement is the situation of reconstruction of existing meanings, which actualizes the identification mechanism, which implies the identification by the student of himself with successful representatives of the future profession, foresight in the context of studying mathematics of his new personal and professional capabilities [11]. Work on updating this situation is based on the use of contextual forms and teaching methods (Table 1).

Table 1. Implementation of the first stage of the experiment.

\begin{tabular}{|c|c|}
\hline \multicolumn{2}{|c|}{ Stage I - the stage of activation of reflection, a critical attitude to the existing meanings of } \\
studying mathematics
\end{tabular}




\begin{tabular}{|c|c|}
\hline \multicolumn{2}{|c|}{$\begin{array}{l}\text { Stage I - the stage of activation of reflection, a critical attitude to the existing meanings of } \\
\text { studying mathematics }\end{array}$} \\
\hline Implemented tasks of the stage: & Activities carried out: \\
\hline $\begin{array}{l}\text { Modeling a problem situation } \\
\text { "Learning objectives"; inclusion in } \\
\text { the dialogue about the meaning and } \\
\text { role of mathematics in the profession } \\
\text { and in the modern world. }\end{array}$ & $\begin{array}{l}\text { Practical lesson on the topic "Why do I (a modern specialist, } \\
\text { a future agricultural worker) need knowledge of } \\
\text { mathematics". } \\
\text { Teaching method: document analysis. } \\
\text { Form of study: web quest, business game, discussion. }\end{array}$ \\
\hline $\begin{array}{l}\text { Modeling the "Success" situation; } \\
\text { activation of cognitive interest by } \\
\text { understanding the significance of the } \\
\text { material in practical activity }\end{array}$ & $\begin{array}{l}\text { Practical lesson on the topic "Mathematics in the } \\
\text { countryside". } \\
\text { Teaching method: task-based - solving applied problems } \\
\text { related to farming. } \\
\text { Form of study: work in small groups. }\end{array}$ \\
\hline Activation of reflexive processes. & $\begin{array}{l}\text { Viewing thematic videos: "Mathematics in everyday life", } \\
\text { "History of the development of mathematics", "Does a } \\
\text { modern person need a mathematician?", "Why knowledge of } \\
\text { mathematics is needed in agriculture" } \\
\text { The lesson is composition. }\end{array}$ \\
\hline
\end{tabular}

The method of document analysis was used to develop students' professional orientation [12], to familiarize themselves with the goals of studying a mathematics course in an agricultural university, designating the place and role of the subject in their professional education.

The business game "I am a professional of the future" made it possible to recreate the content and social content of future professional activities;

Discussion on the topic "Why do I (a modern specialist, a future agricultural worker) need knowledge in mathematics?" contributed to the formation of experience of joint participation in the discussion of theoretical problems.

The content of the practical lesson on the topic "Mathematics in the countryside" is aimed at demonstrating the connection between mathematics and labor in agricultural production. Solving the problems of agricultural practice made it possible to identify the connection between mathematics and the surrounding reality, to make the educational activities of students more meaningful and productive.

Lesson - the essay was conducted with the aim of forming reflective ideas about the specifics of mathematics as an academic discipline and science in general.

The second stage of the experiment consisted in filling abstract mathematical concepts with concrete semantic content; the implementation of interdisciplinary ties was carried out by solving interdisciplinary problems. The means of achievement was the situation of actualization of personal meaning, in which the mechanism of internalization is involved, that is, the process of studying mathematics becomes the content of a personal attitude, expressed in the readiness of students for a certain activity in teaching mathematics. The work on actualizing this situation is based on the method of problem learning, the method of tasks, the method of "unfinished sentences" (Table 2).

Table 2. Implementation of the second stage of the experiment.

\begin{tabular}{|c|c|}
\hline \multicolumn{2}{|c|}{ Stage II - the stage of actualizing personal meaning } \\
\hline Implemented tasks of the stage: & Activities carried out: \\
\hline $\begin{array}{l}\text { Stimulating the formation of meaning; } \\
\text { saturation of the content of the subject with } \\
\text { professional and socially significant contexts. } \\
\text { Increasing the level of activity, the manifestation of } \\
\text { volitional efforts to overcome difficulties. }\end{array}$ & $\begin{array}{l}\text { Contextual type lectures and practical } \\
\text { lessons (problem lecture, lecture - } \\
\text { visualization, lecture with pre-planned } \\
\text { errors). } \\
\text { Lesson "Self-government" }\end{array}$ \\
\hline
\end{tabular}




\begin{tabular}{|l|c|}
\hline \multicolumn{2}{|c|}{ Stage II - the stage of actualizing personal meaning } \\
\hline \multicolumn{1}{|c|}{ Implemented tasks of the stage: } & \multicolumn{1}{c|}{ Activities carried out: } \\
\hline $\begin{array}{l}\text { Implementation of interdisciplinary connections of } \\
\text { mathematics. }\end{array}$ & Solution of interdisciplinary problems. \\
\hline Activation of reflexive processes. & The technique of "unfinished sentences". \\
\hline
\end{tabular}

Stimulation of meaning-making is organized with the help of various forms of contexttype lectures, including a problem lecture (as a challenge, an impetus to a discussion, to a semantic search for a personality), a lecture with pre-planned errors (for the development of critical thinking), a lecture-visualization (with the aim of analysis, synthesis, generalization of information);

The task method contributed to the implementation of intersubject connections. The conditions and requirements of interdisciplinary problems contained components of related subjects.

When organizing the role-playing game "Self-government", students were offered to replace the teacher at certain stages of teaching mathematics (informative report, derivation of a formula, proof of theorems, and explanation of the algorithm for solving problems). Students took the place of a teacher, thus "living" a certain social role, the role of a specialist, a leader. The organization of such a game situation contributed to the manifestation of such indicators of the formation of the meaning of studying mathematics as an increase in the level of activity, the manifestation of volitional effort to overcome difficulties, a conscious acceptance of the importance of studying mathematics.

The use of the "unfinished sentences" technique allowed students to engage in selfanalysis of their own activities. The meaning of the methodology is for the student to independently continue to supplement the phrases received from the teacher. Students finished phrases of the following nature:

1) Today I coped with my work in class, because I ...

2) Today I did not cope with my work in class, because I ...

3) I could complete more tasks if ...

4) My main drawback that manifested itself in the lesson ...

5) My dignity manifested in the lesson ...

6) I wish myself for the next lesson..., etc.

The third stage involves the activities of students aimed at self-education and selfrealization through various forms of organizing the learning process. The goals of the third stage were to activate the creative initiative of students. The means of achievement is the situation of self-realization of meaning, which actualizes the psychological mechanism of exteriorization, involving the translation of accumulated experience. The work to actualize this situation was based on the use of methods for developing the experience of research activities (project teaching method), forms that activate creative thinking (theoretical conference - presentation competition) (Table 3).

Table 3. Implementation of the third stage of the experiment.

\begin{tabular}{|l|l|}
\hline \multicolumn{2}{|c|}{ Stage III - the stage of stimulating self-realization } \\
\hline \multicolumn{1}{|c|}{ Implemented tasks of the stage: } & \multicolumn{1}{|c|}{ Activities carried out: } \\
\hline $\begin{array}{l}\text { Modeling the situation "Realization of } \\
\text { nnowledge of mathematics in practice in the } \\
\text { personal and professional sphere." }\end{array}$ & $\begin{array}{l}\text { Competition of projects on the theme } \\
\text { "Mathematics in our life". }\end{array}$ \\
\hline $\begin{array}{l}\text { Stimulating independent work to expand } \\
\text { knowledge of mathematics and its applications. }\end{array}$ & $\begin{array}{l}\text { Calculation and graphic work "The method of } \\
\text { least squares in determining the dependences } \\
\text { of random variables in agricultural practice." }\end{array}$ \\
\hline
\end{tabular}




\begin{tabular}{|c|l|}
\hline \multicolumn{2}{|c|}{ Stage III - the stage of stimulating self-realization } \\
\hline \multicolumn{1}{|c|}{ Implemented tasks of the stage: } & \multicolumn{1}{|c|}{ Activities carried out: } \\
\hline $\begin{array}{l}\text { The accumulation of experience of self-report, } \\
\text { reflection of their activities. }\end{array}$ & $\begin{array}{l}\text { Round table on the topic "The results of my } \\
\text { educational activities in the study of } \\
\text { mathematics." }\end{array}$ \\
\hline
\end{tabular}

The competition of projects on the topic "Mathematics in our life" contributed to the actualization of students' own efforts aimed at studying the subject, searching for an individual way of knowing; inclusion of students in life creation.

Calculation and graphic work is set with the aim of developing students' skills of independent work and expanding knowledge of mathematics and its applications. The topics of the assignments correspond to the profile of professional training [13].

As a reflection, a round table was organized on the topic "The results of my educational activities in the study of mathematics", at which the teacher together with the students summed up the results of the study of the mathematics course.

In the control group, classes were held in a traditional manner. A traditional lesson in mathematics includes working on theoretical material, solving standard and increased complexity of problems in the textbook, performing thematic tests and independent work.

\section{Results and Discussion}

As a result of the study, four levels of the formation of the personal meaning of the study of mathematics were identified. Low - the level of formal attitude to the process of teaching mathematics; average - the level of positive-amorphous attitude to the process of teaching mathematics; high - the level of an active-cognitive attitude; the highest is the level of value-semantic attitude to the process of teaching mathematics. The methodology for studying levels was the author's methodology of A.P. Novakova, adapted to the subject "Mathematics" [14].

After analyzing the results of the ascertaining and formative experiment, the dynamics of the levels of formation of the personal meaning of the study of mathematics was obtained among students of the experimental and control groups at the beginning and at the end of the work (Fig. 1.). In total, 92 people participated in the experiment.
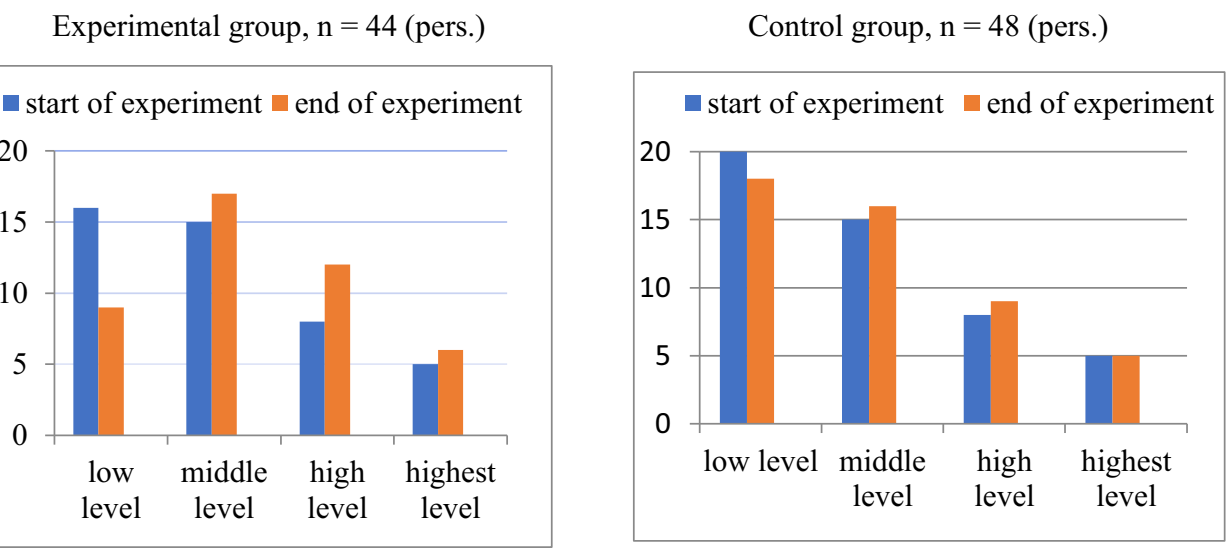

Fig. 1. Dynamics of the levels of formation of personal meanings.

At the ascertaining stage in the experimental groups, a low and medium level of meaning formation was shown by the majority of subjects ( $36 \%$ and $34 \%$, respectively); 
$18 \%$ of students turned out to be representatives of a high level, $12 \%$ of students showed the highest level of the formation of meaning - a value-semantic attitude towards learning.

At the final stage of the experiment, a number of changes were recorded, namely, the transition of students from a low level to an intermediate level (low level - 20\%, middle level - $41 \%$ ). The number of students with high proficiency increased from $18 \%$ to $25 \%$. There are $2 \%$ more students with the highest level of meaning formation.

Thus, in the experimental group, positive dynamics of the development of students' personal meanings was recorded. The number of students with a low level of formal attitude to the process of studying mathematics has decreased; the number of representatives of the middle and high level of meaning formation has noticeably increased. There was a slight positive change in the dynamics of the students with the highest level.

Changes were observed in the development of personal meanings among students of the control groups, but the dynamics of these changes had an insignificant less pronounced character.

The analysis showed that the semantic approach to learning contributes to the acquisition of experience in the search and understanding of meaning, the emergence of doubts about the current attitude to the study of mathematics. Representatives of a low level of personal meaning formation developed a situational interest in the subject in the presence of interesting situations. Cognitive activity was observed when performing tasks of a template nature. Representatives of the middle level in the study of mathematics showed a more consistent interest. Certain types of work in the class caused a surge of positive emotions. High-level representatives were quite active, periodically showed enthusiasm and most often expressed positive emotions. Representatives of the highest level of formation of meaning for the study of mathematics were independent and proactive, which was possible due to the high quality of knowledge in mathematics.

\section{Conclusions}

1. The ratio of the number of students by the levels of sense formation in the experimental and control groups in comparison with the results of the ascertaining experiment confirmed the effectiveness of the chosen model of the educational process in mathematics.

2. The positive dynamics of the development of personal meanings of learning in the experimental part of the study justifies such pedagogical conditions as the activation of reflexive processes, stimulation of the student's subjectivity, saturation of the content of the subject with relevant and significant in the context of issues of the future profession.

3. The trend towards the development of personal meanings has confirmed the effectiveness of using a contextual approach to the process of teaching mathematics.

\section{References}

1. A.A. Kisel, S.P. Hook. Multilevel social reproduction: questions of theory and practice, 1 (16), 236-243 (2011)

2. S.N. Dvoryatkina. Development of the probabilistic style of thinking of students in teaching mathematics based on the dialogue of cultures (thesis abstract for the degree of Doctor of Pedagogy, Elets State University named after I.A.Bunin, Yelets, 2012)

3. E.G. Belyakova, S.N. Degtyarev. Education and Science, Izvestia URO RAO, 3 (82), 3-15 (2011)

4. N.V. Biryukova. Agri-food policy of Russia, 12 (72), 161-164 (2017) 
5. D.A. Leontiev. Psychology of Sense: Nature, Structure and Dynamics of Sense Reality (Moscow: Smysl, 2003)

6. A. G. Asmolov. Psychology of Personality (Moscow: Academy, 2002)

7. V.V. Serikov. Education and personality. Theory and Practice of Designing Pedagogical Systems (Moscow: Publishing Corporation "Logos", 1999)

8. 6.C.B Belova. Pedagogy of dialogue. Theory and Practice of Building a Humanitarian Education: Monograph (Moscow: APKiPPRO, 2006)

9. A.A. Verbitsky. Invariants of Professionalism: Problems of Formation: Monograph (Moscow: Logos, 2011)

10. N.V. Biryukova. Espacios, 39, 20 (2018)

11. A.P. Novakova. Pedagogical conditions for the formation of the meaning of learning a foreign language in future teachers (Diss. Candidate of Pedagogy, Volgograd State Socio-Pedagogical University, 2011)

12. N.V. Biryukova. World of science, culture, education, 2 (75), 193-196 (2019)

13. L.I. Iakobiuk, M.V. Vinogradova, N.N. Malchukova, Y.V. Kryucheva, Espacios, 38, 40 (2017)

14. A.P. Novakova. Bulletin of the Volgograd State Pedagogical University, 4 (48), 52-56 (2010) 